\title{
BEBIDA SEMELHANTE AO ALUÁ UTILIZANDO SUCO DE MELANCIA COMO SUBSTRATO PARA FERMENTAÇÃO CONTROLADA DA BACTÉRIA LÁCTICA LACTOBACILLUS PLANTARUM
}

\author{
Flavia da Silva Carvalho'; ${ }^{1}$ Elinalva Maciel Paulo
}

\author{
1. Bolsista PROBIC/UEFS, Graduanda em Engenharia de Alimentos, Universidade Estadual de Feira de Santana, \\ e-mail: flaviascarvalho01@gmail.com \\ 2. Orientadora, Departamento de Ciências Biológicas, Universidade Estadual de Feira de Santana, e-mail: \\ elinalvamacielpaulo@gmail.com
}

PALAVRAS-CHAVE: Aluá, Fermentação, Bebida

\section{INTRODUÇÃO}

As bactérias láticas pertencem a um grupo de bactérias que tem como principal produto metabólico o ácido lático. A maioria das espécies pertencente a este grupo não é patogênica, a exemplo dos Lactobacillus Plantarum, por isso são utilizadas na elaboração e obtenção de diversos produtos (PAULO, 2010).

Muitos destes produtos são elaborados pela fermentação espontânea do leite, frutas, legumes e sumos vegetais. Um exemplo típico deste tipo de fermentação é o Aluá, que trata-se de uma bebida indígena refrigerante produzida através das cascas de frutas como o abacaxi. Diante do exposto, o grande interesse partiu da necessidade de inovar na área de bebidas fermentadas, onde se produziu uma bebida regional, semelhante ao Aluá, porém com parâmetros controlados, para que futuramente esta bebida consiga adquirir um padrão de qualidade.

\section{MATERIAL E MÉTODOS OU METODOLOGIA}

A cultura de Lactobacillus Plantarum ABX4.1 selvagem, criopreservadas no meio LEL foi reativada, inoculando-a no caldo MRS (DE MAN; ROGOSA; SHARPE, 1960) e incubando-a a $30^{\circ} \mathrm{C}$ por $48 \mathrm{~h}$. Um mínimo de três repiques foi realizado até obter o inoculo. Este procedimento objetiva garantir a total reativação da linhagem que, quando conservada em baixas temperaturas, encontra-se em estado de atividade metabólica extremamente reduzida.

Em relação a produção da bebida fermentada foi utilizado o suco de melancia para preparar a bebida semelhante ao aluá de abacaxi típico da Bahia, porém com adaptações para a produção de uma bebida com parâmetros padronizados, através da fermentação controlada pelo Lactobacillus Plantarum ABX4.1.

Foi inoculado 1\% da cultura de Lactobacillus Plantarum ABX4.1 em 1 litro de suco de melancia. Foi adicionado 1 e 1/2 xícara de açúcar mascavo, 3 cravos da índia sem cabeça e uma colher de chá de gengibre ralado. Foram incubadas em três diferentes condições: $35^{\circ} \mathrm{C}$ por $48 \mathrm{~h}, 6^{\circ} \mathrm{C}$ por 15 dias e $6^{\circ} \mathrm{C}$ por 1 mês. Foi realizada também a fermentação espontânea utilizando o mesmo substrato vegetal (sem ter sido esterilizado) e sem a inoculação da cultura selvagem, sendo incubado por 9 dias em refrigerador. Nos períodos finais de cada incubação foram recolhidas amostras para a determinação de parâmetros físico-químicos ( $\mathrm{pH}$, teor alcoólico, acidez total e açúcar redutor total). 
$\mathrm{O} \mathrm{pH}$ foi determinado em pHmetro digital (Quimis). A acidez total foi realizada conforme Brasil (2005), A determinação do teor alcoólico foi realizada pelo refratômetro e a determinação do açúcar redutor foi conforme Adolfo Lutz (1985).

\section{RESULTADOS E/OU DISCUSSÃO}

De acordo com as análises realizadas no laboratório, foi possível obter os seguintes resultados, - conforme exposto na Tabela 1 - da fermentação controlada e espontânea do suco de melancia pela bactéria Lactobacillus Plantarum ABX 4.1:

Tabela 1. Determinação do pH.

\begin{tabular}{lll}
\hline Fermentação & \multicolumn{1}{c}{ Incubação } & pH \\
Espontânea & $6^{\circ} \mathrm{C} / 9$ dias & 5,83 \\
Controlada & $35^{\circ} \mathrm{C} / 48$ Horas & 3,16 \\
Controlada & $6^{\circ} \mathrm{C} / 15$ dias & 3,82 \\
Controlada & $6^{\circ} \mathrm{C} / 1$ mês & 3,68 \\
\hline
\end{tabular}

Sabemos que o pH da melancia pura é de 5,3. Dessa forma, podemos afirmar que se trata de uma fruta de $\mathrm{pH}$ ácido. Na fermentação espontânea, onde não houve adição de bactéria Lactobacillus Plantarum $A B X 4$.1, na incubação de $6^{\circ} \mathrm{C}$ por 9 dias, logo o pH não sofreu alteração, pois continha apenas a polpa da fruta, sugerindo uma adaptação mais difícil da cultura láctica a este substrato. Na fermentação controlada, onde houve a adição da bactéria Lactobacillus Plantarum ABX 4.1, no período de incubação de $35^{\circ} \mathrm{C}$ por 48 horas, houve alteração do $\mathrm{pH}$, que foi de 3,16 . Essa bebida foi a mais ácida, devido a cultura láctica ter crescido no substrato, conferindo um sabor mais ácido a bebida. $\mathrm{Na}$ incubação de $6^{\circ} \mathrm{C}$ por 15 dias, o pH estava em 3,82 . Isso informa que a bactéria se desenvolveu bem e caso ficasse mais tempo no período de incubação, ela cresceria mais e ofereceria um sabor mais ácido. Na incubação de $6^{\circ} \mathrm{C}$ por $1 \mathrm{mês,} \mathrm{o} \mathrm{pH}$ estava em 3,68. O período de incubação sendo maior, em torno de 1 mês, a cultura láctica se desenvolveu mais do que na incubação $6^{\circ} \mathrm{C}$ por 15 dias. Vale ressaltar que, a fermentação mais ácida, que ocorreu na incubação de $35^{\circ} \mathrm{C}$ por 48 horas, teve esse desenvolvimento devido às condições de temperatura e tempo terem sido as mais favoráveis a bactéria láctica.

Tabela 2. Determinação da Acidez Total.

\begin{tabular}{|lccccc|}
\hline Fermentação & Incubação & \%Acidez 1 & \%Acidez 2 & \%Acidez 3 & $\begin{array}{c}\text { \%Acidez } \\
\text { Total }\end{array}$ \\
Espontânea & $6^{\circ} \mathrm{C} / 9$ dias & 0,17 & 0,33 & 0,26 & 0,22 \\
Controlada & $35^{\circ} \mathrm{C} / 48 \mathrm{~h}$ & 1,23 & 1,17 & 1,29 & 1,23 \\
Controlada & $6^{\circ} \mathrm{C} / 15$ dias & 0,38 & 0,46 & 0,30 & 0,38 \\
Controlada & $6^{\circ} \mathrm{C} / 1$ mês & 0,87 & 0,33 & 0,87 & 0,69 \\
\hline
\end{tabular}




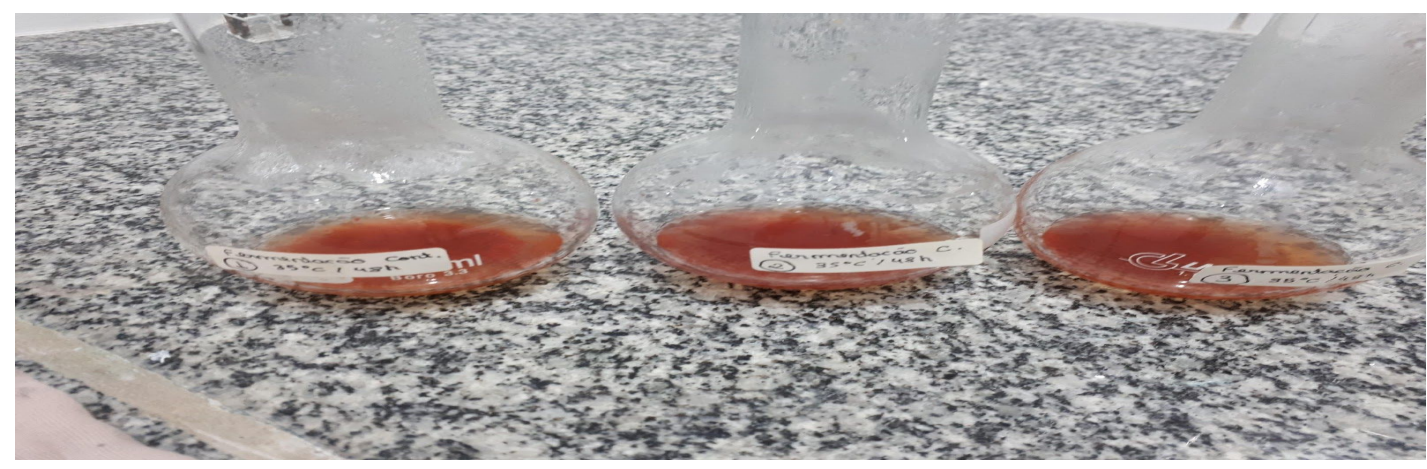

Figura 1: Triplicatas da determinação da Acidez Total.

A Acidez Total de uma determinada amostra está relacionada a porcentagem de acidez que um determinado alimento ou bebida possui. Na Tabela 2, podemos visualizar que dentre todas as incubações, a que possui maior porcentagem de acidez foi a Fermentação Controlada a $35^{\circ} \mathrm{C} / 48$ horas, onde a Figura 1 nos mostra a coloração da bebida após as análises de acidez. Isso ocorreu devido a cultura láctica ter se desenvolvido melhor a essa temperatura e tempo, como foi possível comprovar através do $\mathrm{pH}$, em torno de 3,12. A baixa acidez dos frutos de melancia atrai muitos consumidores cujo valor máximo médio observado se mantém na faixa obtida em outros trabalhos e também dentro do intervalo de $\mathrm{pH}$ desejável pelo mercado consumidor (Andrade Júnior et al., 2006). A fermentação com menor porcentagem de acidez foi a espontânea, com $0,22 \%$ e um pH de 5,38. Analisando em conjunto, o pH com a acidez, concluímos que quanto maior o $\mathrm{pH}$ do suco, menos ácido ele será ou quanto menor o pH mais ácido o suco se tornará.

Tabela 3. Determinação do açúcar redutor.

\begin{tabular}{|lccccc|}
\hline Fermentação & Incubação & $\begin{array}{c}\text { \%Açúcar } \\
\text { redutor 1 }\end{array}$ & $\begin{array}{c}\text { \%Açúcar } \\
\text { redutor 2 }\end{array}$ & $\begin{array}{c}\text { \%Açúcar } \\
\text { redutor 3 }\end{array}$ & $\begin{array}{c}\text { \%Açúcar } \\
\text { redutor } \\
\text { Total }\end{array}$ \\
Espontânea & $6^{\circ} \mathrm{C} / 9$ dias & 19,47 & 20,14 & 17,71 & 19,10 \\
Controlada & $35^{\circ} \mathrm{C} / 48 \mathrm{~h}$ & 14,78 & 18,01 & 19,49 & 17,42 \\
Controlada & $6^{\circ} \mathrm{C} / 15$ dias & 16,20 & 17,92 & 19,28 & 17,80 \\
Controlada & $6^{\circ} \mathrm{C} / 1$ mês & 18,15 & 16,55 & 18,41 & 17,70 \\
\hline
\end{tabular}

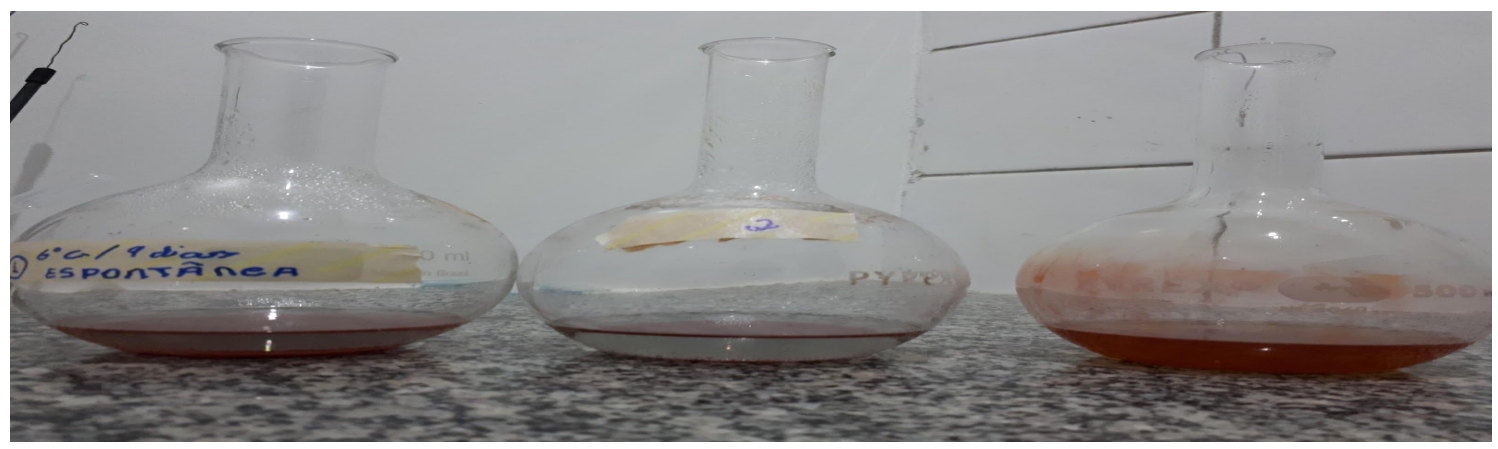

Figura 2: Triplicatas da determinação do açúcar redutor. 
Através dos resultados obtidos na Tabela 3, foi possível analisar que a fermentação que obteve maior redução de açúcar foi a fermentação controlada a $35^{\circ} \mathrm{C}$ por 48 horas, como é exemplificado na Figura 2, justamente por se tratar de uma bebida ácida onde o açúcar foi reduzido em torno de $17,42 \%$. Isso indica que as demais bebidas não obtiveram uma redução do açúcar, devido a bactéria láctica não ter se desenvolvido tão bem nesta fermentações quanto na de $35^{\circ} \mathrm{C}$ por 48 horas.

\section{CONSIDERAÇÕES FINAIS}

Ao final deste projeto de pesquisa podemos afirmar que o substrato de melancia utilizado para preparar as bebidas fermentadas com parâmetros físico-químicos controlados é um bom substrato, pois foi possível observar através dos resultados obtidos que a bactéria láctica Lactobacillus Plantarum $A B X \quad 4.1$ isolada e criopreservada no Laboratório de Microbiologia Aplicada a Saúde Pública (LAMASP) se desenvolveu bem e conferiu características físico-químicas agradáveis. A acidez e pH obtiveram valores considerados bons para uma possível padronização da bebida e futuramente comercialização da mesma.

\section{REFERÊNCIAS}

PESSOA, Ticiana; FIGUEIRÊDO, Rossana M. F.; AMARAL, Denise Silva; GURJÃO, Flavio Farias; CARNEIRO, Gilmara Gurjão ; MOURA NETO, Luis Gomes. Avaliação físicas e físico-químicas de frutos de melancia comercializados da empresa paraibana de abastecimento de produtos agrícolas (EMPASA). Campina Grande, PB, BRASIL. Disponível em: http://congressos.ifal.edu.br/index.php/connepi/CONNEPI2010/paper/viewFile/1443/52 2. Acesso: 10 de Agosto de 2018.

DEMIATE, Ivan Mottin; WOSIACKI, Gilvan; CZELUSNIAK, Cristina; NOGUEIRA, Alessandro. Determinação de açúcares redutores e totais em alimentos. Comparação entre método colorimétrico e titulométrico. Disponível em: http://www.pitangui.uepg.br/GTM/Menu/Volume04/artigo23.pdf. Acesso: 10 de Agosto de 2018.

O pH dos alimentos. Disponível em: https://www.portaleducacao.com.br/conteudo/artigos/nutricao/o-ph-dos-alimentos/5211 4. Acesso: 10 de Agosto de 2018.

Andrade Júnior, A. S.; Dias, N.da S.; Figueiredo Júnior, L. G. M.; Ribeiro, V. Q.; Sampaio, D. B. Produção e qualidade de frutos de melancia à aplicação de nitrogênio via fertirrigação. Revista Brasileira Engenharia Agrícola e Ambiental, v.10, p.836-841, 2006.

Produção e qualidade da melancia submetida a adubação nitrogenada. Disponível em: http://www.scielo.br/pdf/rbeaa/v16n10/a07.pdf. Acesso: 11 de Agosto de 2018.

RAMOS, Anamaria RP; S DIAS, Rita de Cássia; ARAGÃO, Carlos Alberto. Densidades de plantio na produtividade e qualidade de frutos de melancia. Disponível em: http://www.scielo.br/pdf/hb/v27n4/26.pdf. Acesso: 13 de Agosto de 2018. 